\title{
Emergency peripartum hysterectomy: a retrospective study of 7 years
}

\author{
Suchith Hoblidar*, Sunil Kumar K. S., Ratnamala M. Desai
}

Department of Obstetrics and Gynaecology, SDM College of Medical Sciences and Hospital, Sattur, Dharwad, Karnataka, India

Received: 16 July 2016

Accepted: 09 August 2016

\section{*Correspondence:}

Dr. Suchith Hoblidar,

E-mail: suchith.hoblidar@gmail.com

Copyright: (C) the author(s), publisher and licensee Medip Academy. This is an open-access article distributed under the terms of the Creative Commons Attribution Non-Commercial License, which permits unrestricted non-commercial use, distribution, and reproduction in any medium, provided the original work is properly cited.

\section{ABSTRACT}

Background: Emergency peripartum hysterectomy (EPH) is a rare but a lifesaving procedure done as a last resort to save life of mother. We conducted this study to know the incidence, leading causes, risk factors and complications of EPH.

Methods: We conducted a retrospective analysis of all the patients who underwent EPH from January 2008 to December 2015 at SDMCM and H. All patients who underwent EPH from 22 weeks of gestation to 6 weeks postpartum were included in the study.

Results: There were 21 emergency peripartum hysterectomies, with deliveries during the same period being 27271 and the rate of EPH was 0.7 per 1000 deliveries. Most common indication for EPH was uterine atony (38\%), followed by uterine rupture $(23.8 \%)$ and morbidly adherent placenta (19\%). Most of the patients $(47.6 \%)$ had previous cesarean deliveries. EPH was done following cesarean in $66.6 \%$. Subtotal hysterectomy was done in $61.9 \%$. Intra-operative urinary bladder injury was seen in $14.2 \%$ of the patients.

Conclusions: Uterine atony and uterine rupture continues to be the most common causes for EPH in our population. Multiparity is an important risk factor among patients with rupture uterus. Cesarean delivery and repeat cesarean deliveries are the likely risk factors for EPH.

Keywords: Emergency peripatum hysterectomy, Previous cesarean, Uterine rupture

\section{INTRODUCTION}

Emergency peripartum hysterectomy is a rare but a very challenging obstetric procedure. It is done as a last resort to save the life of a parturient mother in case of severe haemorrhage. Incidence of emergency peripartum hysterectomy varies from region to region. It varies between 0.24-8.9 per 1000 deliveries. ${ }^{1}$ Incidence depends on the availability of good antenatal and obstetric care. It also depends on education of the patient and general health care awareness of the society. Incidence also varies with the mode of delivery. EPH (emergency peripartum hysterectomy) following vaginal delivery is constant and varies between $0.1-0.3$ per 1000 vaginal deliveries 1 . EPH following caesarean section varies widely between 0.17 -
8.7 per 1000 caesarean deliveries as it depends on other factors like presence of morbidly adherent placenta. ${ }^{1}$

EPH includes hysterectomies done during caesarean section and after vaginal delivery or any time within the puerperium. ${ }^{2} \mathrm{EPH}$ is a very challenging procedure, as the patient would be critically ill and since it is rare, expertise among obstetricians is minimal. Indications for EPH have been changing over years. Uterine atony and rupture uterus are now being replaced by abnormal placentation as a major cause of EPH1. This is because of vigilant care given during labor to prevent prolonged labor and also early management of atonic PPH (postpartum haemorrhage) with uterotonic agents. This change may also be due to the increasing tendency towards caesarean deliveries which predisposes to abnormal placentation. 
Severe post-partum haemorrhage continues to be the leading cause of maternal deaths accounting for $27.1 \%$ of deaths worldwide. ${ }^{3}$ There has been a steady rise in incidence of post-partum haemorrhage, in spite of there being great advances in availability of better drugs for conservative management of postpartum hemorrhage. ${ }^{4}$

A meta-analysis showed that incidence of obstetric hysterectomy has been increasing at the rate of $8 \%$ annually. ${ }^{5}$ Risk factors for EPH include advanced maternal age, multiparity, previous caesarean, uterine myoma , placenta previa ,induced labor, operative vaginal delivery, caesarean delivery and fetal macrosomia. ${ }^{6}$ Early identification of risk factors, good antenatal and obstetric care, early referral to tertiary centre would certainly help in preventing obstetric hysterectomies and reducing maternal mortality.

We conducted this study to know the incidence, patient profile, indications and complications of EPH.

\section{METHODS}

This was a retrospective observational study conducted at the SDM College of Medical Sciences and Hospital Dharwad. This institution is a teaching hospital, and is a major referral center for nearby villages.

We included all women undergoing hysterectomy after 22 weeks of gestational age and within 6 weeks of delivery from January 2008 to December 2015 for a period of 7 years.

Information's about the patients undergoing EPH were collected from the parturition and operation registers. Medical records and operation notes of all women who underwent peripartum hysterectomy were scrutinized. The study included women who were referred to our hospital either for delivery or after delivery with severe postpartum hemorrhage, apart from patients who were booked at our hospital.

Patient characteristics such as age, parity, history of previous cesarean or curettage, type of antenatal care, mode of delivery, type of hysterectomy were documented. Details regarding newborn were recorded. Intra-operative complications if any and post-operative morbidity such as fever, urinary tract infection, need for blood transfusion and duration of hospital stay were recorded.

\section{RESULTS}

There were 27271 deliveries from January 2008 to December 2015. A total of 21 Emergency peripartum hysterectomies were performed with the incidence being 0.7 per 1000 deliveries in our institution.

Thirteen $(61.9 \%)$ patients were referred from nearby hospitals, with $8(38.0 \%)$ being referred after delivery, with $3(14.2 \%)$ of the referred patients suspected to be having ruptured uterus. Most of the patients were multiparous 19 (90.4\%). Maternal age was between 2236 years with mean being $27.6 \pm 3.7$ years. The mean gestational age at which EPH was performed was $36.6 \pm 4.2$ weeks. There was $1(4.7 \%)$ between $22-28$ weeks, $5(23.8 \%)$ between $28-36$ weeks and $15(71.4 \%)$ above 36 weeks.

Table 1: Demographic and clinical data of 21 women who underwent emergency peripartum hysterectomy.

\begin{tabular}{|ll|}
\hline Characteristics & Values \\
\hline Mean maternal age (years) & $27.6 \pm 3.7$ \\
\hline Mean parity & 1.7 \\
\hline Mean gestational age (weeks) & $36.6 \pm 4.2$ \\
\hline Delivery by CS (number, \%) & $14(66.6 \%)$ \\
\hline History of previous CS (number, \%) & $10(47.6 \%)$ \\
\hline Previous 1 CS (number, \%) & $8(38.0 \%)$ \\
\hline Previous 2 CS (number, \%) & $1(4.8 \%)$ \\
\hline Previous 3 CS (number, \%) & $1(4.8 \%)$ \\
\hline Prior uterine curettage (number, \%) & $1(4.8 \%)$ \\
\hline Patients with uterine rupture (number, \%) & $4(19 \%)$ \\
\hline
\end{tabular}

EPH was done for atonic PPH in 8 (38.0\%), followed by uterine rupture in $5(23.8 \%)$ and morbidly adherent placenta in $4(19.0 \%)$. EPH was done for secondary $\mathrm{PPH}$ in $3(14.3 \%)$ and for traumatic PPH in $1(4.8 \%)$ of the patients. Obstructed labor was seen in $4(80 \%)$ of the patients with rupture uterus and all were referred from periphery. All these patients were multiparous with 3 (60\%) being gravida 3 and above. There was one rupture following instrumental vaginal delivery. All the 4 (100 $\%$ ) patients with adherent placenta had history of previous caesarean.

Table 2: Indications for emergency peripartum hysterectomy.

\begin{tabular}{ll}
\hline Indications & Number (\%) \\
\hline Uterine atony & $8(38 \%)$ \\
\hline Uterine rupture & $5(23.8 \%)$ \\
\hline Morbidly adherent placenta & $4(19 \%)$ \\
\hline Traumatic postpartum haemorrhage & $1(4.8 \%)$ \\
\hline Secondary postpartum haemorrhage & $3(14.3 \%)$ \\
\hline
\end{tabular}

Table 3: Complications with emergency peripartum hysterectomy.

\begin{tabular}{|ll|}
\hline Complications & Number $(\%)$ \\
\hline Mean blood transfusion units & 3.9 \\
\hline Bladder injury & $3(14.2 \%)$ \\
\hline Acute kidney injury & $1(4.8 \%)$ \\
\hline Septicemia & $2(9.5 \%)$ \\
\hline Pressure sore & $2(9.5 \%)$ \\
\hline Death & $1(4.8 \%)$ \\
\hline
\end{tabular}

EPH was done following caesarean delivery in 14 $(66.6 \%)$ and following vaginal birth in $3(14.3 \%)$ of the patients. The remaining $4(19.0 \%)$ patients had uterine 
rupture with fetus in the peritoneal cavity. Of the 14 patients for whom EPH was done following caesarean delivery $4(28.5 \%)$ had primary caesarean delivery and $10(71.4 \%)$ had repeat caesarean delivery. Indications for primary caesarean deliveries were abruption in $2(50 \%)$, fetal distress in $1(25 \%)$ and failure of delivery of the second twin in another $1(25 \%)$. Of the 10 patients with repeat caesarean delivery, $6(60 \%)$ had central placenta previa, among whom $4(66.6 \%)$ had morbidly adherent placenta.

The mean birth weight of the new-born was $2.5 \pm 0.8 \mathrm{~kg}$. There were 5 fresh still births of which 4 patients had uterine rupture.

Subtotal hysterectomy was performed in $13(61.9 \%)$ and total hysterectomy in $8(38.0 \%)$ of the patients. Hysterectomy was done immediately following delivery in $12(57.1 \%)$, within first week in $6(28.5 \%)$ and within a fortnight in 1 (4.7\%). EPH was done for secondary post-partum haemorrhage in 2 patients, in one of whom it was done after 20 days and in another patient after 40 days.

Most common intra-operative complication in our study was haemorrhage with all patients requiring transfusion of blood and blood products. A mean of 3.9 units of packed red blood cells were transfused. Intra-operative injury to the urinary bladder was seen in 3 (14.2\%) of the patients. All the 3 patients had previous caesarean deliveries. There were no other intra-operative complications. Post-operative septicemia was seen in 2 (9.5\%) of the patients, one of whom was managed conservatively and the other patient died on the 14th post-operative day due to multi-organ damage. Acute kidney injury was seen in $1(4.7 \%)$ of the patients requiring 2 haemodialysis. Pressure sore, requiring skin grafting had developed in $2(9.5 \%)$ of the patient. Duration of hospital stay was between 5-60 days with mean being $16.7 \pm 12.3$ days.

\section{DISCUSSION}

Obstetricians have been performing EPH since the last 100 years. The first successful EPH was performed in 1876 by Eduardo Porro, Professor of Obstetrics at Pavia to control hemorrhage and prevent peritonitis. ${ }^{7}$

Incidence of EPH in our study was 0.7 perm 1000 deliveries which were in comparison with Fatu Forna et al. ${ }^{8}$ This was similar to the study done by Chawla et al where the incidence was 0.8 per 10002 . Since the time $\mathrm{EPH}$ has been in obstetric practice, indication for the same has been constantly changing. Older studies show that EPH was performed for sterilization, defective uterine scar, uterine myoma and other gynecological conditions. Later in the 1980's it was done for uterine atony and rupture uterus. The most common indication for EPH in developed countries at present is morbidly adherent placenta. Kastner et al. found placenta accreta to be the the most common indication for EPH. ${ }^{9}$ In the same population Clark et al. found uterine atony to be the common indication in 1984, whereas in 1993 Stanco et al. reported placenta accreta to be the most common cause followed by uterine atony. ${ }^{10,11}$ This shows that there has been a changing trend where morbidly adherent placenta has taken over uterine atony as the major cause for EPH. This change has been attributed to better management of postpartum hemorrhage with uterotonic agents and also due to increase in cesarean deliveries. But this change is yet to reflect in our population as uterine atony still continues to be leading cause for EPH in our study followed by uterine rupture and placenta accreta similar to findings of study done by Chester et al. ${ }^{12}$ Most of the patients in our study were referred patients where vaginal delivery had been tried and some were referred after a possible diagnosis of rupture uterus. Most cases of rupture uterus were due to obstructed labor in our study, indicating poor obstetric management. There has been ample attempt in training birth attendants in early detection of high risk cases, effective use of partogram and effective management of postpartum hemorrhage with uterotonic agents. But the present study shows that there is need for early referral and improving access to better obstetric care.

Identifying risk factors and patients at high risk for EPH is very important in reducing maternal morbidity and mortality. Risk factors include maternal age $\geq 35$ years, multiparity, previous cesarean delivery, primary and repeat cesarean deliveries, vaginal birth after cesarean and multiple pregnancy. ${ }^{6,13}$ Mean age of patients in our study was $27.6 \pm 3.7$ years which similar to the findings of Saxena et al. ${ }^{14}$ Younger age of our patients is possibly because our hospital caters to rural population where education level is lower and age at marriage among women is lower. Whiteman et al observed that peripartum hysterectomy increased with increasing maternal age. ${ }^{13}$

According to the study by Whiteman et al, cesarean delivery is associated with higher risk of EPH because of labor complications and also as the uterus is more easily removable surgically. ${ }^{13}$ Even in our study majority of EPH were done following cesarean delivery which was similar to the findings of Forna et al. ${ }^{8}$ We found that $47.6 \%$ of our patients had previous cesarean delivery. Flood et al noted that previous cesarean delivery increases the risk of EPH and it is mostly attributable to morbidly adherent placenta. ${ }^{7}$ We found that all the patients with morbidly adherent placenta had history of previous cesarean delivery. This finding is similar to the findings of Kastner et al who found that $95.6 \%$ of patients with placenta accreta had previous cesarean. ${ }^{9}$ According to Whiteman et al rate of EPH was lowest with vaginal delivery with rate increasing with primary cesarean delivery, vaginal birth after cesarean and repeat cesarean deliveries and opined that the highest risk was with repeat cesarean deliveries. ${ }^{13}$

We found that $61.9 \%$ of our patients were multiparous. This was similar to the findings of Kastner et al. where $72.3 \%$ of women undergoing EPH were multiparous. ${ }^{9}$ 
Even though there was no grand multipara in our study, there were $36 \%$ of patients who were gravida 3 and above.

Subtotal hysterectomy was done in $61.9 \%$ and total hysterectomy in $38 \%$ of our patients. This observation was similar to the findings of Najam et al who found $79.1 \%$ of the EPH were subtotal hysterectomies. ${ }^{15}$ Due to the risk of cervical stump carcinoma and the need for regular screening total hysterectomy has been recommended wherever possible. ${ }^{1}$ Subtotal hysterectomy has the advantage of reduced blood loss, lesser operating time and reduced intra and postoperative complications. ${ }^{16}$ Kastner et al. noted that with better screening and reducing incidence of cervical stump cancer subtotal hysterectomy could be feasible method during emergencies. ' With cervical cancer being the leading cause of cancer related deaths among women in India, women for whom subtotal hysterectomy has been done should be advised to undergo periodic screening for cervical cancer. However total hysterectomy has to be performed in case of bleeding from lower uterine segment so as to tackle cervical branch of uterine artery and also in cases where placenta is placed in lower uterus. ${ }^{1}$

Most common intra-operative complication in our study was hemorrhage followed by urinary bladder injury. All these patients with urinary bladder injury had previous cesarean delivery with associated adhesions between bladder and lower uterine segment.

\section{CONCLUSION}

From this study we found uterine atony and uterine rupture are still the two leading causes for EPH indicating there is a need for improvement in obstetric care. With increasing rate of caesarean the incidence of morbidly adherent placenta and the requirement for EPH is possibly going to increase. Better obstetric care, early referral and reduction in primary caesarean deliveries will definitely help in reducing the need for EPH thereby go a long way in improving maternal health.

\section{Funding: No funding sources}

Conflict of interest: None declared

Ethical approval: The study was approved by the Institutional Ethics Committee

\section{REFERENCES}

1. Lovina SM. Machado. Emergency peripartum hysterectomy: incidence, indications, risk factors and outcome. North American Journal of Medical Sciences. 2011;3(8):358-61.
2. Chawla J, Arora CD, Ajmani SN. Emergency Obstetric hysterectomy: a retrospective study from a teaching hospitalin North India over eight years. Oman Med J. 2015;30(3):181-6.

3. Say L, Chou D, Gemmill A, Tnncalp Ö, Moller AB, Daniels J, et al. Global causes of maternal death: a WHO systematic analysis. Lancet Glob Health. 2014;2(6):e323-33.

4. Cameron CA, Roberts CL, Olive EC, Ford JB, Fischer WE. Trends in postpartum hemorrhage. Aust N Z J Public Health. 2006;30(2):151-6.

5. Tuncalpo O, Hindin MJ, Souza JP, Chou D, Say L. The prevalence of maternal near miss: a systematic review. BJOG. 2012;119(6):653-61.

6. Carvalho JF, Cubal A, Torres S, Costa F, da Carmo O. Emergency peripartum hysterectomy: a 10- year review. International Scholarly Research Network Emergency Medicine, 2012. Available at http://www.hindawi.com/journals/isrn/2012/721918/.

7. Flood KM, Said S, Geary M, Robson M, Fitzpatrick $\mathrm{C}$, Malone FD. Changing trends in peripartum hysterectomy over last 4 decades. Am J Obstet Gynecol. 2009;200:632.e1-632e6.

8. Forna F, Miles AM, Jamieson DJ. Emergency peripartum hysterectomy: a comparision of cesarean and postpartum hysterectomy. Am J of Obstetrics and Gynecology. 2004;190:1440-4.

9. Kastner ES, Figueroa R, Garry D, Maulik D. Emergency peripartum hysterectomy: experience at a community teaching hospital. Obstetric and Gynecology. 2002;99(6):971-5.

10. Clark SL, Yeh SY, Phelan JP, Bruce S, Paul RH. Emergency hysterectomy for obstetric hemorrhage. Obstet Gynecol. 1984;64:376-80.

11. Stanco LM, Schrimmer DB, Paul RH, Mishell DR. Emergency peripartum hysterectomy and associated risk factors. Am J Obstet Gynecol. 1993;168:879-83.

12. Chester J, Sindhu P, Sharma S, Israfil-Bayli F. Emergency peripartum hysterectomy at a district general hospital in United Kingdom: 10-Year Review of Practice. 2016;2016:Article ID9875343:4.

13. Whiteman MK, Kuklina E, Hillis SD, Jamieson DJ, Meikle SF, Posner SF, et al. Incidence and determinants of peripartum hysterectomy. Obstet Gynecol. 2006;108(6):1486-92.

14. Saxena SV, Bagga R, Jain V, Gopalan S. Emergency peripartum hysterectomy. International Journal of Gynecology and Obstetrics. 2004;85:172-3.

15. Najam R, Bansal $P$, Sharma R, Agarwal D. Emergency obstetric hysterectomy: a retrospective study at a tertiary care hospital. Journal of Clinical and Diagnostic Research. 2010;(4):2864-8.

16. Chanrachakul B, Chaturachinda K, Phuspradit W, Roungsipragarn R. Cesarean and postpartum hysterectomy. Int J Gynecol Obstet. 1996;54(2):10913.

Cite this article as: Hoblidar S, Kumar KS, Desai RM. Emergency peripartum hysterectomy: a retrospective study of 7 years. Int J Reprod Contracept Obstet Gynecol 2016;5:3112-5. 